\title{
O Processo de Trabalho em Enfermagem e Os Recursos Humanos: a Humanização em Construção
}

\author{
Guedes, Giovanna Carolina; Nicola, Anair Lazari; Moraes, Aluana; Rodrigues, Daisy \\ Cristina; Cavalheiri, Jolana Cristina \\ Universidade Estadual do Oeste do Paraná — giocguedes@hotmail.com
}

Introdução: o Programa Nacional de Humanização da Assistência Hospitalar (PNHAH) foi instituído pelo Ministério da Saúde no ano de 2001. Teve como principal objetivo melhorar as relações entre os profissionais da saúde e usuários, bem como dos profissionais entre si e do hospital com a comunidade. o programa foi elaborado a partir das referências dos usuários, que se queixavam sobre a deficiência no atendimento hospitalar (BRASIL, 2001). para a implantação do PNHAH foram criados Grupos de Trabalho de Humanização Hospitalar. Esses grupos seriam os elementos agregadores e difusores do conceito de humanização, contemplando os conceitos subjetivos e éticos, bem como as propostas do programa. no seu processo de trabalho, o enfermeiro tem como foco principal o desenvolvimento do cuidado e o gerenciamento de enfermagem e para atender as constantes transformações nas organizações de saúde, busca utilizar modelos gerenciais capazes de assegurar aos usuários uma assistência integral por meio da humanização. Objetivo: Realizar um relato de experiência sobre a humanização e o gerenciamento em enfermagem para a alta hospitalar. Método: Esta pesquisa consistiu em um relato de experiência que descreve aspectos vivenciados pelas residentes de enfermagem em gerenciamento de enfermagem em clinica médica e cirúrgica. o relato de experiência é uma ferramenta de pesquisa que tem por objetivo realizar uma reflexão sobre uma ação ou uma situação identificada. Resultados: Durante o período que permanecemos nas unidades foi possível evidenciar que os profissionais compreendem o processo de humanização para a assistência. no entanto quando observada a sua prática durante a assistência foi identificado que não existe o numero necessário de profissionais para realizar o cuidado humanizado, tornando a assistência fragmentada. Essas ações são decorrentes de inúmeros fatores, entre eles, o modelo gerencial, a cultura institucional, ausência de dimensionamento adequado dos profissionais e a sobrecarga de trabalho que acaba gerando absenteísmo entre os profissionais de saúde. Ficou evidenciado que a instituições de saúde precisam aprimorar seu ambiente de trabalho, a fim que o mesmo torne-se favorável e adequado para que os enfermeiros realizem uma assistência humanizada. Conclusão: a instituição deve ser provedora dos meios para que os profissionais possam realizar a assistência de acordo com os pressupostos da humanização. a falta de infraestrutura e o déficit de profissionais são fatores que influenciam diretamente na assistência. Portanto, faz-se necessário ressaltar, que os pressupostos da humanização não sejam vistos de modo isolado por uma categoria profissional, mas articulada com as dimensões políticas e administrativas das instituições.

Guedes, Giovanna Carolina; Nicola, Anair Lazari; Moraes, Aluana; Rodrigues, Daisy Cristina; Cavalheiri, Jolana Cristina. O Processo de Trabalho em Enfermagem e Os Recursos Humanos: a Humanização em Construção. In: Anais do Congresso Internacional de Humanidades \& Humanização em Saúde [= Blucher Medical Proceedings, num.2, vol.1]. São Paulo: Editora Blucher, 2014. ISSN 2357-7282

DOI 10.5151/medpro-cihhs-10748 